\title{
Studies on the Absorption and Metabolism of Folic Acid
}

\author{
I. FOLATE ABSORPTION IN THE DOG AFTER EXPOSURE \\ OF ISOLATED INTESTINAL SEGMENTS TO SYNTHETIC \\ PTEROYLPOLYGLUTAMATES OF VARIOUS CHAIN LENGTHS
}

\author{
C. M. Baugh, C. L. Krumdieck, H. J. Baker, and C. E. Butterworth, Jr. \\ From the Nutrition Program of the Departments of Medicine and Pediatrics, \\ in collaboration with the Department of Comparative Medicine, University of \\ Alabama School of Medicine, Birmingham, Alabama 35233
}

A B S T RACT Folic acid absorption was studied in anesthetized dogs by determining the amount and chemical nature of folate in venous blood emerging from isolated intestinal segments containing free folic acid and/ or pteroylpolyglutamates of a known chain length. Chromatographically pure test materials placed in the lumen were prepared by unambiguous solid phase synthetic methods. This synthetic procedure not only yields compounds of known structure, it also provides a means by which glutamic acid residues at any given position in the gamma glutamyl chain can be made radioactive. For example, teropterin (pteroyltriglutamate) was synthesized in such a way that ${ }^{14} \mathrm{C}$ was present only in the middle glutamic acid unit. Suitable placement of label permitted assessment of the extent of peptide cleavage. The action of plasma conjugase was inhibited by copper chloride. Plasma samples were analyzed by Lactobacillus casei and Streptococcus faecalis assay, by column chromatography, and by quantitative measurement of pteridine-bound radioactivity.

It was observed that biologically active folate appeared in the mesenteric vein with either pteroylmono-, di-, tri-, penta-, or heptaglutamate in the lumen. Generally speaking the absorption rate appeared to be inversely related to the length of the gamma glutamyl side chain. Roughly twice as much folic acid appeared in the circulation from ${ }^{3} \mathrm{H}$-labeled pteroylmonoglutamate as from ${ }^{14} \mathrm{C}$-labeled pteroylpentaglutamate when equimolar amounts of each were placed simultaneously in a single intestinal segment. Pteroylmonoglutamate appeared to be the predominant form entering the blood from each of the precursors tested. However, evidence was obtained that

Received for publication 8 May 1970 and in revised form 10 March 1971. pteroyldiglutamate may enter the mesenteric vein soon after placing pteroyldi-, or triglutamate in the lumen, but not with the higher polyglutamates. Comparison of radioactivity and biological activity patterns suggests little conversion, if any, to reduced or methylated forms during the first $30 \mathrm{~min}$ of passage through the intestinal mucosa. We conclude that both pteroylmonoglutamates and pteroyldiglutamates may cross the intestinal mucosa of the $\mathrm{dog}$, and that reduction and methylation are not essential to the absorption process.

\section{INTRODUCTION}

The transfer of folic acid across cell membranes has been a topic of lively interest since the vitamin was first discovered. One of the earliest observations was the fact that certain dietary components, later found to be pteroylpoly- $\boldsymbol{\gamma}$-glutamates, are active in the chick antianemia system, but are inactive as microbial growth factors without prior enzymic degradation (1). Current interest stems not only from a need to define the availability of these natural food folates as vitamin sources for man, but also from a need for better understanding of the function of pteroylpoly- $\boldsymbol{\gamma}$-glutamates in physiologic events within cells.

Unfortunately, the study of the intestinal absorption of pteroylpoly- $\gamma$-glutamates has been impeded by a lack of chemically defined test material and by the need to rely on imprecise biological assay procedures. This has resulted in considerable confusion and, in some cases, grossly contradictory results. For example, Whitehead and Cooper (2) have reported that orally administered pteroylmonoglutamate is absorbed unaltered into the portal circulation of humans undergoing umbilical vein catheterization. On the other hand, Chanarin and Perry 
(3) concluded that the same molecule is reduced and methylated by the intestine during the process of intestinal absorption. Two reports $(4,5)$ suggest that pteroylpolyglutamates must be converted to a monoglutamyl form if absorption is to occur, yet Baker, Franks, and Sobotka (6) have suggested that pteroylmonoglutamate requires the addition of two glutamic acid units during the absorption process. Two groups have suggested that diphenylhydantoin interferes with the enzymic cleavage of pteroylpoly- $\gamma$-glutamates $(7,8)$ while two other groups $(9,10)$ found no such effect.

There is considerable evidence that the length of the gamma glutamyl chain is a key factor affecting cellular permeability to folic acid. For example, the assay organism, Lactobacillus casei, can incorporate and utilize pteroylglutamates having one, two, or three glutamyl residues, but fails to grow when presented with folates having four or more glutamates in the chain. Similarly, Streptococcus faecalis is capable of using mono- and diglutamyl forms of folate to meet its nutritional needs, but shows no growth in the presence of folates having three or more glutamyl residues. Enzymic degradation of the longer chains to an appropriate length produces growth-supporting activity for both organisms from inactive precursors (1).

Once inside the cell, folic acid is apparently restored to a polyglutamate stage. The subject of pteroylpolyglutamate formation has been discussed and studied by Wood and Wise (11), who postulate that polyglutamate formation normally precedes formylation. It is of interest to note that a variety of enzymes have been described as having a requirement for the tetrahydropteroylglutamate cofactor in the polyglutamate form $(12,13)$. While some of these are capable of partial function with the corresponding monoglutamyl derivative, we are aware of no situation in which the monoglutamyl structure is more active. Indeed, the monoglutamyl derivative has been demonstrated to be an inhibitor in the cobalamin-independent pathway involving the methylation of homocysteine to form methionine (14) It seems likely that the predominance of pteroylpolyglutamates in foods is due to the fact that this is the naturally occurring, functional form of the vitamin. Similarly, it is reasonable to postulate that elongation of the gamma glutamyl peptidechain favors retention of the molecule within the cell, while shortening it would favor passage out of the cell. For example, the folic acid lost in urine $(15,16)$ is readily assayable without prior conjugase treatment and on chromatography appears to be in the monoglutamyl form $(17,18)$. Likewise, the folic acid lost in bile does not require deconjugation for measurement and is present in a concentration several times greater than that of blood plasma $(19,20)$.

A procedure has recently been developed (21) based on the solid-phase peptide synthesis techniques of Merrifield (22) for the production of pteroylpolyglutamates of known structure and in good yield. This procedure has permitted the synthesis of pteroylpolyglutamates selectively labeled in the glutamate chain. The nature of the procedure is such that a preselected amino acid can be built into the growing peptide chain at any chosen point. After each stepwise addition to the end of the chain the unreacted reagents are quantitatively washed away, leaving the resin bound peptide. In this way a uniformly ${ }^{14} \mathrm{C}$-labeled glutamate unit can be placed selectively among nonradioactive glutamate units in series according to the sequence of reagents employed in the chemical synthesis. Because the reactions are controlled and directed, the number of amino acids in the chain is always known, and the location of the radioactive package is governed by the synthetic protocol. For example, when four of the complex reaction cycles have been completed, it is known that the product has reached the tetrapeptide stage. Any incomplete chains are blocked from further growth by an acetylation reaction between steps. Coupling with pteroic acid produces a pteroylpolyglutamate corresponding to the number of peptidation reactions accomplished. The resulting product now has the spectral properties of the heterocyclic ring system and characteristic chromatographic properties attributable to the number of carboxyl residues in the peptide chain. Chromatographic reisolation from DEAE cellulose columns gives a pure product in high yield. These compounds have greatly facilitated studies concerning the polyglutamate portion of the folate molecule.

In an earlier study (23) involving human subjects, it was observed that pteroylpolyglutamates are cleaved to a monoglutamyl stage either during the process of intestinal absorption or very soon thereafter. However, it was not possible in that study to determine if cleavage occurred in the intestine or in other tissues, such as the liver, after absorption from the intestine had occurred. In this report we wish to describe investigations in which it was possible to identify the chemical structure of folate entering the portal circulation from isolated intestinal segments of anesthetized dogs. Since only prehepatic blood was examined, the liver was excluded as a possible site for metabolic modification of the folate molecule. Further precautions were taken by collecting blood samples into a dilute solution of copper chloride to prevent alterations of the absorbed compounds by plasma conjugase. Observations were made on four different, specifically labeled, unambiguously synthesized pteroylpolygammaglutamates. These included the di-, tri-, penta, and heptaglutamyl forms of folic acid in addition to conventional pteroylglutamic acid (PGA). ${ }^{1}$ The test ma-

\footnotetext{
${ }^{1}$ In this discussion PGA is referred to as the monoglutamate. All references to polyglutamates are to the gamma-
} 
terial was instilled directly into the lumen by passing a small needle through the intestinal wall. The nature of the compound(s) entering the portal circulation was ascertained by radioactive tracer techniques, by differential microbiological assays, and by chromatography using synthetic compounds as either reference standards or carriers for cochromatography.

\section{METHODS}

Experimental animals. Well nourished mongrel dogs weighing $14-18 \mathrm{~kg}$ were used in this study. Each animal was treated for gastrointestinal parasites (Dichlorvos 45 $\mathrm{mg} / \mathrm{kg}$ and Niclosamide $160 \mathrm{mg} / \mathrm{kg}$ ), immunized against rabies and held for at least 14 days before use. All animals were fasted for 12-14 hr before surgery. No evidence of parasitic infestation was found at the time of the surgical procedure. Histologic sections prepared from small bowel biopsy at the termination of each experiment revealed normal morphologic structure

Surgical procedure. Preoperative analgesia was induced with an injection of Fentanyl and Droperidol or Thiamylal. Light surgical anesthesia was induced and maintained through the use of halothane in a closed intratracheal system. All animals received $0.4 \mathrm{mg}$ of atropine sulfate immediately after induction of anesthesia.

The abdomen was opened through a midline incision and hemostasis was secured. A $10 \mathrm{~cm}$ segment of jejunum was identified $20-30 \mathrm{~cm}$ distal to the ligament of Treitz. Segments were selected so that a thin-walled polyethylene catheter $\left(0.965 \mathrm{~mm}\right.$ o.D. "Intracath ${ }^{\circledR}$ ") could be passed from a vessel in an adjacent segment to the point of bifurcation of the mesenteric vein draining the segment under study. Clamps isolated the intestinal lumen while ligatures prevented the sampling of blood other than that of the test segment. During the sampling procedure retrograde flow of blood from elsewhere in the portal system was prevented by gentle digital occlusion at a point just cephalad to the junction with the cannulated branch. In this way the entire venous effluent could be directed through the cannula when desired. Test materials were placed in the intestinal lumen by careful transmural injection with a 20 gauge needle and syringe, after which the solution was gently distributed through the lumen.

In some experiments, two segments of jejunum were isolated in the same animal, care being taken to prepare segments of comparable size and blood supply. In these studies the longer chain polyglutamates were placed in the more proximal test segment.

Labeled compounds. Tritiated folic acid, labeled in positions $3^{\prime}$ and $5^{\prime}$ of the PABA moiety was obtained commercially ${ }^{2}$ and chromatographically repurified before use. Folic acid-2- ${ }^{14} \mathrm{C}$ was purchased ${ }^{3}$ and similarly purified before

polypeptides only. Position 1 is the position occupied by the glutamyl residue attached to the $p$-aminobenzoic acid moiety of pteroic acid. Pt-G is used as an abbreviation for pteroyl. monoglutamate; PtGG for the diglutamate, PtGGG for the triglutamate, and so on. An asterisk is used after a letter to indicate the location of the radioactive label. For example, $\mathrm{Pt} * \mathrm{G}$ is folic acid labeled in the pteroate moiety, while $\mathrm{PtGG} * \mathrm{G}$ represents pteroyltriglutamate labeled in the middle glutamic acid unit. The term conjugase is used as a synonym for pteroylpolygamma glutamyl carboxypeptidase.

${ }^{2}$ Nuclear-Chicago Corp., Des Plaines, Ill.

${ }^{3}$ New England Nuclear Corp., Boston, Mass. use. Pteroylpolyglutamates, bearing uniformly labeled glutamic acid units at selected positions, were synthesized by the solidphase method as previously described (21). The purified products were desalted and adjusted to $\mathrm{pH}$ 7.0. Quantities were determined spectrophotometrically on the basis of molar extinction coefficients.

Microbiological assays. Microbiological assays were carried out with Streptococcus faecalis ATCC 8043 and Lactobacillus casei ATCC 7469. The assays were done using the appropriate folate free media ${ }^{4}$ and standard procedures employed in this laboratory (23). All assays were performed in triplicate and the values reported here are averages of the three determinations.

Inhibition of plasina conjugase and sampling. In order to ascertain whether or not alterations in the polyglutamyl side chain were occurring at or in the cut wall, it was considered necessary to inhibit the plasma conjugase. Preliminary in vitro studies indicated that $0.1 \mathrm{ml}$ of $0.02 \mathrm{M} \mathrm{CuCl}_{2}$ would completely inhibit the action of plasma conjugase in as much as $12 \mathrm{ml}$ of whole blood. Accordingly, $0.1 \mathrm{ml}$ of $0.02 \mathrm{M} \mathrm{CuCl}_{2}$ was added to each heparinized tube before the addition of blood specimens collected from the mesenteric vein. This concentration of $\mathrm{CuCl}_{2}$ was demonstrated not to interfere with the microbiological assay for folic acid by either L. casei or S. faecalis.

The determination of radioactivity. Total plasma radioactivity was determined by counting $0.1 \mathrm{ml}$ of plasma in 10 $\mathrm{ml}$ of counting fluid. ${ }^{5}$ Noncharcoal adsorbable radioactivity was determined as follows : $1.0 \mathrm{ml}$ of plasma was mixed with $1.0 \mathrm{ml}$ of $5 \%$ trichloroacetic acid (TCA) and the precipitated proteins removed by centrifugation. The clear supernatant $(1.0 \mathrm{ml})$ was added to $1.0 \mathrm{ml}$ of a $5 \%$ charcoal suspension in $0.1 \mathrm{~m}$ acetate buffer $\mathrm{pH} 4.5$. The charcoal was removed by filtration through a disposable Milliport filter (Millipore Corp., Bedford, Mass.). $\frac{1}{2} \mathrm{ml}$ of the filtrate was counted in $10 \mathrm{ml}$ of scintillation fluid of the following composition: naphthalene, $120.0 \mathrm{~g}$; 2,5-diphenyloxazole, $7.0 \mathrm{~g} ; 1,4$-bis (2-[5-phenyloxazolyl])-benzene, $50 \mathrm{mg}$; $p$-dioxane to 1 liter. These data permit quantitative estimation to be made on the ratio of free glutamic acid-C ${ }^{14}$ to pteridine-bound glutamic acid- $\mathrm{C}^{14}$ at the time of sampling.

Radioactivity was monitored in the column eluates by counting $1.0 \mathrm{ml}$ portions from each fraction in $10 \mathrm{ml}$ of the $p$-dioxane/naphthalene counting fluid containing $4 \%(\mathrm{w} / \mathrm{v})$ Cab-o-sil ${ }^{6}$ to prevent precipitation of $\mathrm{NaCl}$.

Radioactivity measurements were-made with a Scintillation Spectrometer (Unilux I Model). ${ }^{7}$ All samples were counted for a sufficient period of time to give $5 \%$ or less error in the counting. Efficiency of counting was determined by the channel ratio method. Counting data are reported as either cpm or dpm. In the latter case, figures have been extrapolated to $100 \%$ efficiency.

Column chromatography. Folic acid and its various gammaglutamyl derivatives were purified by chromatographic procedures developed in this laboratory (21). The elution pattern from a standard diethylaminoethyl cellulose chloridecolumn ("DEAE") of a previously purified mixture of synthetic pteroylmono, -di, and -trigammaglutamates is shown in Fig. 1. The order of elution of the various poly- $\gamma$-glutamates is reproducible and if sufficient care is devoted to duplication in packing the columns, these chromatographic procedures are useful in identifying the various polygam-

${ }^{4}$ Difco Laboratories, Detroit, Mich.

5 "Scintisol," Isolab, Inc., Elkhart, Ind.

"Cabot Corporation, Boston, Mass.

${ }^{7}$ Nuclear-Chicago Corp., Des Plaines, I11. 


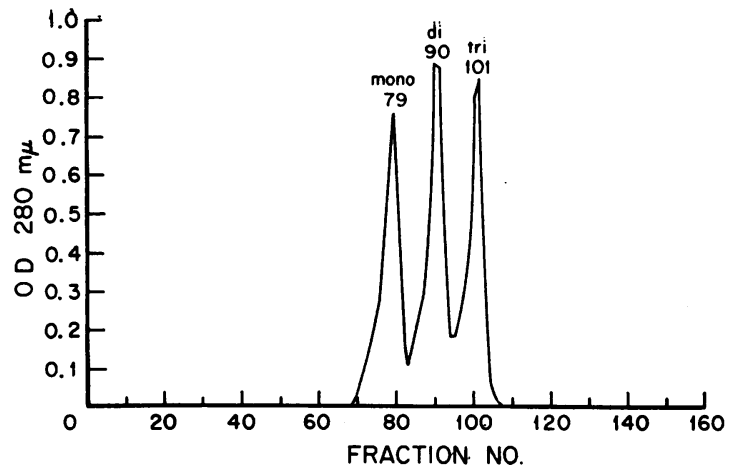

Figure 1 "Standard" DEAE-cellulose chloride column purification of synthetic pteroylglutamates. The peak centered at fraction 79 represents $\mathrm{Pt}-\mathrm{G}$, that at fraction 90 represents $\mathrm{Pt}-\mathrm{GG}$, while that at fraction 101 represents $\mathrm{Pt}$ GGG. See text for details.

maglutamates. A $1 \times 20 \mathrm{~cm}$ column was packed with DEAEcellulose in the chloride form. The folic acid compounds were applied from dilute $(0.1 \mathrm{M})$ salt concentrations at $\mathrm{pH}$ 7.0. The columns were developed with a linear gradient brought about with 1 liter of $0.005 \mathrm{M}$ phosphate buffer, $\mathrm{pH}$ 7.0 , in the mixing chamber and 1 liter of $0.5 \mathrm{M} \mathrm{NaCl}$ in 0.005

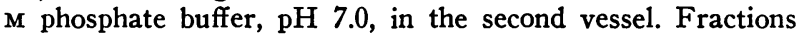
of $12.5 \mathrm{ml}$ were collected. This chromatographic procedure is referred to as the "standard" procedure throughout the text. Plasma samples were prepared for chromatography by precipitating proteins with an equal volume of $5 \%$ trichloracetic acid.

\section{RESULTS}

\section{Chromatography of reference standards}

The results of "standard" chromatographic separation of pteroylmono-, di-, and triglutamates are shown in Fig. 1.

\section{Pteroyldiglutamate}

A. $3 \mu$ moles of $\mathrm{PtGG}^{*}$ in a volume of approximately $10 \mathrm{ml}$, were placed in the lumen of an isolated segment as described. Heparinized blood samples, $10 \mathrm{ml}$ each, were obtained at 5 -min intervals for $45 \mathrm{~min}$. Microbiological assays were not performed, but there was a linear increase in radioactivity during the sampling period. Charcoal treatment of plasma removed all radioactivity from samples collected during the 1 st $30 \mathrm{~min}$ indicating that the ${ }^{14} \mathrm{C}$ was bound to pteridine. The sample collected at 45 min contained low levels of radioactivity which did not bind to charcoal indicating that it was no longer covalently bound to the folic acid molecule.

The plasma remaining from all samples was pooled and applied to a DEAE column, as described, along with $1 \mu$ mole each of authentic, nonradioactive PtG and PtGG. The results presented in Fig. 2 indicate that a significant portion of the administered material has entered the mesenteric circulation without prior cleavage. Any free folic acid absorbed under these conditions would not be radioactive and would not be detected in the monoglutamate elution zone. However, there was no radioactivity in the triglutamate elution zone either, indicating no synthesis of this molecule from the starting material.

Recovery. At the end of the experiment the intestinal segment was excised. Radioactivity measurements on lumen contents plus several washings indicated a recovery of $24 \%$ of the administered dose. Virtually all radioactivity recovered $(95 \%)$ was charcoal adsorbable, and therefore bound to pteridine.

B. In the second experiment, the same dose of PtGG* was injected into an isolated intestinal segment of another animal prepared in the same manner. However, in this procedure a peripheral infusion of saline was administered to aid in the maintenance of blood volume and all blood emerging from the segment was collected fractionally into heparinized tubes. The flow rate provided a $5 \mathrm{ml}$ blood sample at intervals of approximately $2 \mathrm{~min}$ during the sampling period of $11 \mathrm{~min}$. At that time a clot prevented further sampling.

A plot of the plasma radioactivity and microbiological activity with $S$. faecalis indicated parallel absorption curves. The net folic acid absorption as determined by $S$. faecalis assay, was calculated by subtracting the fasting folate value from all samples (Table I). It was found that the specific activity of the folate absorbed into the mesenteric vein was $1,883,077 \mathrm{dpm} / \mu$ mole. This finding indicates some dilution due to absorption of pteroylmonoglutamate but during this sampling period over three-fourths of the folate is entering the circulation as the diglutamate. $L$. casei assays were not performed. Again it was possible to show by cochromatography with authentic material, that the radioactivity was pres-

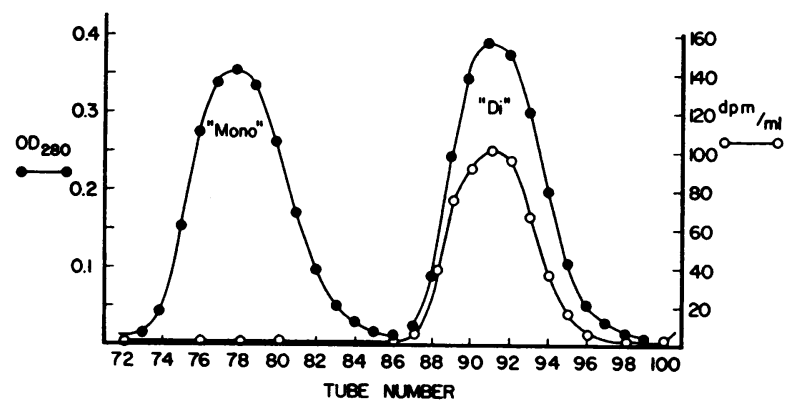

Figure 2 Cochromatography of pooled mesenteric plasma samples with authentic pteroylmono-, and diglutamate, after instillation of pteroylglutamyl- $\mathrm{U}^{14} \mathrm{C}$ glutamate (PtGG*) into the lumen. Note that radioactivity is recovered in the "diglutamate" elution zone, indicating the absorption of intact pteroyldiglutamate. No radioactivity was observed in the "triglutamate" elution zone indicating that none of the administered material had been converted to the "triglutamate." 
TABLE I

Changes in Plasma Folate Activity and Radioactivity during Continuous Sampling of Mesenteric Vein after Instillation of Pteroylglutamyl-U $U^{14} C$-glutamate

$\left(P t G G^{*}\right)$ in the Intestinal Lumen

\begin{tabular}{ccccc}
\hline $\begin{array}{c}\text { Sample } \\
\text { time }\end{array}$ & $\begin{array}{c}\text { Total } \\
\text { radioactivity }\end{array}$ & $\begin{array}{c}\text { Radioactivity } \\
\text { nonadsorbable } \\
\text { on charcoal }\end{array}$ & $\begin{array}{c}\text { Pteridine-bound } \\
\text { radioactivity } \\
\text { (column 1-column })\end{array}$ & $\begin{array}{c}\text { Folate activity } \\
\text { S. faecalis }\end{array}$ \\
\hline min & & $d p m / m l$ & & $n g / m l$ \\
0 & 0 & 0 & 0 & $1.25,1.25$ \\
1 & 0 & 0 & 0 & 2.50 \\
1.5 & 0 & 0 & 0 & 11.25 \\
2.5 & 0 & 0 & 0 & 22.50 \\
3.5 & 0 & 0 & 0 & 51.25 \\
4.5 & 0 & 0 & 0 & 54.58 \\
5.5 & 576 & 0 & $576^{*}$ & 57.50 \\
7.0 & 432 & 0 & 432 & 88.75 \\
8.0 & 480 & 0 & 480 & 108.75 \\
9.5 & 1008 & 576 & 432 & 152.50 \\
11.5 & 1104 & 576 & 528 & 170.00 \\
13.0 & contaminated & - & - & -180.00 \\
15.5 & 1584 & 1056 & 528 & 280 \\
\hline
\end{tabular}

* Values indicated by italic numbers were pooled for the calculation of the specific activity of plasma folate after subtracting base line values. The specific activity is $1,883,077 \mathrm{dpm} / \mu$ mole, while that of the starting material was $2,311,450 \mathrm{dpm} / \mu$ mole. This indicates a dilution of about one-fourth by nonradioactive folate.

ent in the same form as the administered compound. A pattern identical to that seen in Fig. 2 was obtained. There was no radioactivity in the triglutamate elution zone. On the basis of these two experiments, we conclude that during the early phases of intestinal absorption, pteroyldiglutamate may be absorbed as such.

Recovery. The lumen contents were recovered and combined with washings as before. In addition, the intestinal segment was separately homogenized and radioactivity measurements were performed on the proteinfree supernate, after precipitation of protein with trichloroacetic acid. It was found that the lumen contained $44 \%$ of the original radioactivity. The soluble extract of the intestinal wall yielded a total of $8.0 \%$ of the dose. Since the effluent blood contained less than $1 \%$ of the administered dose, approximately $48 \%$ of the dose is not accounted for. This suggests that a large portion of the administered folate may have been bound to cellular constituents and precipitated with trichloroacetic acid.

\section{Pteroyltriglutamate and pteroyldiglutamate}

As in the preceding experiments, a segment of proximal jejunum was prepared near the ligament of Treitz, but a second segment was also prepared approximately $25 \mathrm{~cm}$ distally. When cannulas were ready for sampling, $3.44 \mu$ moles of $\mathrm{PtGG} * \mathrm{G}$ was placed in the proximal segment and $3.0 \mu$ moles of PtGG* was placed in the distal segment. Mesenteric blood samples were taken alternately from each segment on the same schedule of elapsed time from the start of the experiment. Three determinations were made on plasma at each point; radioactivity, $L$. casei activity, and $S$. faecalis activity. The results are presented in Fig. 3.

It may be seen that throughout the collection period of $30 \mathrm{~min}$, the folate in the mesenteric samples from both loops has the same properties, i.e., it is radioactive and it supports the growth of both test organisms. This combination of results could occur only if absorption is taking place as the diglutamate. If absorption were occurring as the "tri" or as a methylated tetrahydrofolate, there would be no growth supporting ability for $S$. faecalis; if absorption were occurring as the "mono," the folate would not be radioactive. This experiment also indicates that reduction to tetrahydrofolate is not occurring to any appreciable extent, since this compound loses biological activity under the conditions of autoclaving which were employed (24).

It is possible to make some general observations about absorption rate on the basis of the data, although this was not the purpose of the experiment and the wide divergence of the slopes of the curves was not expected. Each segment was roughly the same size, but there could have been minor differences in inner surface area and blood supply. However, it seems unlikely that these factors could have accounted for a six-fold difference in folate concentration after $30 \mathrm{~min}$. The fact that the 




FIGURE 3 Comparison of radioactivity and biological folate activity in plasma samples from mesenteric vein during exposure of lumen to either $\mathrm{PtGG} *$ or $\mathrm{PtGG} * \mathrm{G}$. The radioactivity curves have been corrected so as to indicate only pteridine-bound- ${ }^{14} \mathrm{C}$ (by subtracting the radioactivity not adsorbable by charcoal). In each case the results indicate that virtually all folate present is in the diglutamyl form, since the "mono-" would not be radioactive and the "tri" would not support the growth of $S$. faecalis. Although the two intestinal segments in this animal may not have been strictly comparable, the difference in slope of the two sets of curves suggests that the triglutamate is handled differently and converted more slowly to an assimilable form. The difference in absorption rate is confirmed by the recovery of $81 \%$ of the radioactivity in the triglutamate loop and only $57 \%$ in the diglutamate loop at the end of 30 $\min$.

proximal small bowel is apparently the main site of folate absorption (25) is not relevant here since greatest absorption occurred in the more distal segment. These observations are strengthened by a similar experiment (see part 5, A and B below) and by an experiment in which differential isotope labeling permitted a comparison of absorption rates from different compounds placed in the same intestinal segment (see part 5, C below).

Recovery. The lumen contents and washings from the proximal segment, containing the pteroyltriglutamate, yielded $81 \%$ of the original radioactivity. The distal segment yielded $57 \%$ of the dose. These results are in keeping with the greater absorption of pteroyldiglutamate already described.

\section{Pteroyltriglutamate}

A. In this experiment $3.0 \mu$ moles of $\mathrm{PtGG}^{*} \mathrm{G}$ were placed in the isolated intestinal segment as previously described. Blood samples were obtained at 5-min intervals for $30 \mathrm{~min}$. Plasma from these specimens was assayed for folate activity with both $L$. casei and $S$. faecalis. Total radioactivity as well as charcoal-adsorbable radioactivity was determined. These results are presented in Table II.

It may be seen that the pteridine-bound radioactivity reaches a peak at about $20 \mathrm{~min}$ and then declines. However, biological activity for the two test organisms continues to rise, indicating continued absorption of folate as the monoglutamate. The relatively greater activity for $S$. faecalis is unexplained. The plasma remaining from all samples, after preliminary testing, was combined and added to an equal volume of $10 \%$ trichloroacetic acid. After contrifugation the supernate was adjusted to $\mathrm{pH} 7.0$ for application to a DEAE column. The results of DEAE chromatography under standard conditions may be seen in Fig. 4. Although the peaks are not widely separated, it may be seen that the largest peak corresponds to the monoglutamate zone of elution around tube 80 .

Due to the small amount of total radioactivity in these fractions, it was not possible to determine a radioactive profile. In order to obtain adequate concentrations of radioactivity, the peaks of $L$. casei active material were divided into four separate pools (I, II, III, and IV) as indicated by the vertical bars in Fig. 4. Samples were prepared for radioactivity determinations by pipeting $4.0 \mathrm{ml}$ from each pool into a scintillation vial and evaporating the water under a heating lamp and blower to a volume of approximately $0.5 \mathrm{ml}$. Each vial then received $10 \mathrm{ml}$ of scintillation fluid containing $4 \%$ Cab-O-

TABLE II

Plasma Folate Activity and ${ }^{14} \mathrm{C}$ Radioactivity in Samples of Mesenteric Venous Blood during Exposure of



\begin{tabular}{|c|c|c|c|c|c|}
\hline \multirow{2}{*}{$\begin{array}{l}\text { Sample } \\
\text { time }\end{array}$} & \multirow{2}{*}{$\begin{array}{c}\text { Total } \\
\text { radioactivity }\end{array}$} & \multirow{2}{*}{$\begin{array}{l}\text { Radioactivity } \\
\text { nonadsorbable } \\
\text { on charcoal }\end{array}$} & \multirow{2}{*}{$\begin{array}{l}\text { Pteridine-bound } \\
\text { radioactivity } \\
\text { (column 1-column 2) }\end{array}$} & \multirow{2}{*}{$\frac{\text { Folate activity }}{\text { L. casei }}$} & \multirow{2}{*}{$\frac{\text { Folate activity }}{S . \text { faecalis }}$} \\
\hline & & & & & \\
\hline $\min$ & & $d p m / m l$ & & & \\
\hline 5 & 1056 & 0 & 1056 & 136 & 180 \\
\hline 10 & 2064 & 576 & 1488 & 175 & 243 \\
\hline 20 & 2856 & 1056 & 1800 & 265 & 388 \\
\hline 25 & 3312 & 1728 & 1584 & 297 & 515 \\
\hline 30 & 3168 & 1680 & 1488 & 357 & 635 \\
\hline
\end{tabular}






Figure 4 Pt-GG*G experiment. Profile of $L$. casei activity in the fractions obtained from the "standard" DEAEcellulose chromatography of the pooled plasma samples. Fractions were combined to give pools I-IV as shown.

sil. The bar graph in Fig. 5 summarizes the radioactivity and biological assay data for these pools.

It may be seen that the folate represented by pool III possesses the most radioactivity. The specific activity of this pool, based on $L$. casei assay, is $1,990,000 \mathrm{dpm} /$ $\mu$ mole. This is in close agreement with the specific activity of the starting mataerial: $1,892,000 \mathrm{dpm} / \mu$ mole. It is concluded that this pool consists of relatively pure pteroyldiglutamate derived from the starting material and absorbed as such.

The larger pool of biologically active material, pool II, has elution properties of pteroylmonoglutamate. In theory, it should be nonradioactive, although calculations indicate that this pool has a specific activity of 265,000 $\mathrm{dpm} / \mu$ mole. The most reasonable explanation for this finding is partial contamination from pool III. An examination of Fig. 4 indicates the likelihood of some admixture of the two compounds in the zone between the two peaks. It is concluded that this pool consists largely of pteroylmonoglutamate derived from the starting material by $\gamma$-glutamylpeptidases in the gut lumen or wall. No further attempts were made to identify the material in pools I and IV. Although the latter is in a position corresponding to the elution zone of pteroyltriglutamate, it differs from the starting material by being nonradioactive. It is likely that pools I and IV represent endogenous folate (see Fig. 9).

The over-all interpretation of this experiment is that PtGG may be absorbed as such, and that as time passes, there is relatively more absorption of $\mathrm{PtG}$, which becomes the predominating form. It was not possible to demonstrate absorption of any PtGGG, and there was nothing in the bioassay results to suggest conversion to the $N^{\mathrm{s}}$-methyl derivative.

The lumen contents were not examined. However, a portion of the pooled plasma sample was subjected to chromatography on Dowex $50-\mathrm{H}^{+}$. Glutamic acid- ${ }^{14} \mathrm{C}$ was recovered by cochromatography with a nonradioactive reference sample. No attempt was made to quantitate this recovery since glutamic acid readily enters the Krebs cycle by deamination and the label is rapidly oxidized to carbon dioxide (23).

B. In the second experiment $3.4 \mu$ moles of PtGG*G were instilled into the intestinal lumen as before. Sequential sampling indicated a prompt rise in plasma radioactivity and biological activity for each of the two test organisms. However, $S$. faecalis activity continued to rise after $L$. casei activity and radioactivity began to decline. This is the same pattern as observed in the previous experiment, Table I. It indicates continued folate absorption after cleavage of glutamates in positions 2 and 3. At no time did the $L$. case $i$ activity exceed $S$. faecalis, indicating very clearly that there was no significant absorption of the triglutamate and that there was no conversion to the $N^{5}$-methyl derivative.

Chromatography of pooled plasma samples revealed significant radioactive labeling only in the elution zone corresponding to the pteroyldiglutamate. These results confirm those in the previous section.

Recovery. At the end of $30 \mathrm{~min}$, the lumen contents were analyzed in each of the three modalities. Recoveries, expressed as percentage of the starting material were as follows: S. faecalis, $26 \%$; L. casei, $41 \%$; radioactivity, $43 \%$.

These results show good agreement between the $L$. case $i$ and radioactivity and indicate the detection of a compound which cannot be detected by $S$. faecalis, the triglutamate. The low levels of $S$. faecalis activity in the lumen, and the contrasting high levels in plasma suggest that the mono- and diglutamate are absorbed rather rapidly.

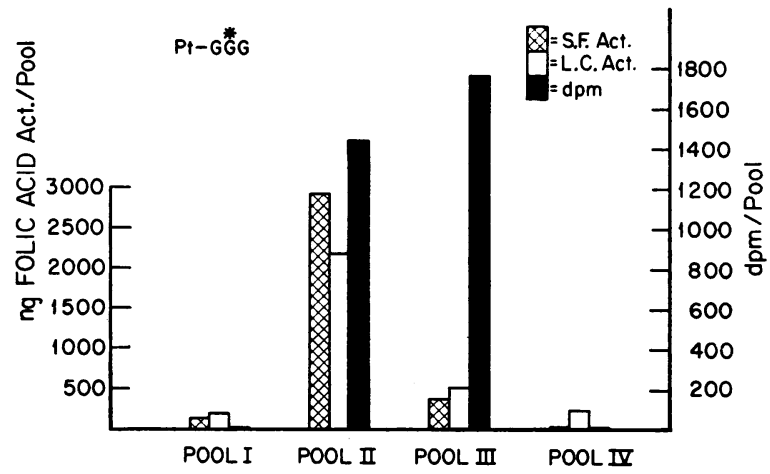

Figure 5 Pt-GG*G experiment. Radioactivity and microbiological activity in pools I-IV of Fig. 4. Pool III appears to be relatively pure $\mathrm{Pt}-\mathrm{GG}^{*}$ having a specific activity of $1,990,000 \mathrm{dpm} / \mu$ mole compared with $1,892,000 \mathrm{dpm} / \mu$ mole of the Pt-GG*G injected into the intestinal lumen. Pool II appears to contain a small amount of Pt-GG* and a large amount of $\mathrm{Pt}-\mathrm{G}$, due to some overlap in the separation of peaks. The specific activity of Pool II is $265,000 \mathrm{dpm} / \mu$ mole. 




FIGURE 6 Composite graph from experiments III, V, and VI drawn to the same scale and prepared for the purpose of making general comparisons as to folate absorption from various pteroylpolyglutamates placed in the intestinal lumen. Although the different intestinal segments were not strictly identical, efforts were made to prepare comparable segments of approximately $10 \mathrm{~cm}$ length in every case. Doses employed were as follows: $\operatorname{dog}$ A, $2.0 \mu$ moles "penta," 2.3 $\mu$ moles "mono;" $\operatorname{dog}$ B, $3.44 \mu$ moles "tri," $3.0 \mu$ moles "di ;" $\operatorname{dog}$ C, $3.0 \mu$ moles "hepta." When two segments were prepared in the same animal, the shorter chain was placed in the more distal segment. It may be seen that the rate and quantity of folate absorption tends to diminish as the length of the polyglutamate chain increases. See also Fig. 7.

\section{Pteroylmonoglutamate and pteroyl- pentaglutamate}

A. In this experiment two separate segments were prepared in the same animal as in part 3 (above). A solution containing $2.0 \mu$ moles of $\mathrm{PtG}^{*}(\mathrm{G})$, was placed in the lumen of the proximal segment while the more distal segment received $2.3 \mu$ moles of $\mathrm{Pt}^{*} \mathrm{G}$. The results of $L$. case $i$ folate-assay on plasma samples from the respective loops are presented in Fig. 6 (dog A). It may be seen that the pteroylmonoglutamate is absorbed more rapidly and within $10 \mathrm{~min}$ reaches a plasma concentration some six times as great as in plasma emerging from the segment exposed to pteroylpentaglutamate. These patterns were confirmed in each case by $S$. faecalis assay and radioactivity determinations.
B. A second animal was prepared and the studies in part A were repeated using the same compounds and amounts. However, blood was not collected in timed fractions. A continuous sample was collected from each loop over a period of $4 \mathrm{~min}$ beginning $15 \mathrm{~min}$ from the time of instilling test material in the lumen. As in the preceding experiment, the plasma concentration of folate was 8-10 times greater in blood draining the monoglutamate segment. The radioactivity levels correlated well with bacteriological assay results. Again there was no disproportion between $L$. casei and $S$. faecalis activity indicating that neither compound was absorbed as the triglutamate or as the $N^{\mathrm{s}}$-methyl derivative.

Because blood was obtained over a timed sampling interval of $4 \mathrm{~min}$, it is possible to make an estimate of absorption rates. The vessel draining the "mono" segment yielded $35 \mathrm{ml}$ of blood and a total of $17,100 \mathrm{ng}$ of $S$. faecalis active folate in the plasma. The other segment yielded $30 \mathrm{ml}$ of blood containing a total of $1375 \mathrm{ng}$ of folate in the plasma derived from "pentaglutamate." Since each segment was approximately $10 \mathrm{~cm}$ long, absorption was occurring at a rate of $425 \mathrm{ng} / \mathrm{min}$ per $\mathrm{cm}$ for the monoglutamyl form of folate. The absorption

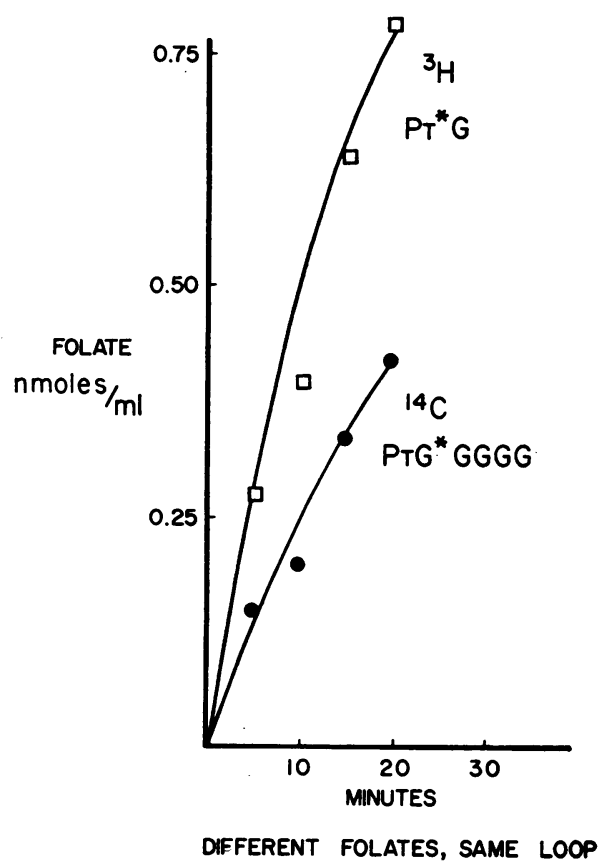

FIGURE 7 A comparison of the early absorption rates of folate after the placement of equimolar amounts of tritiumlabeled pteroylmonoglutamate and ${ }^{14} \mathrm{C}$-labeled pteroylpentaglutamate in the same intestinal segment. It is evident that the label appears more rapidly with the monoglutamate. At $20 \mathrm{~min}$ about twice as much folate has been absorbed from the "mono" as from the "penta." 


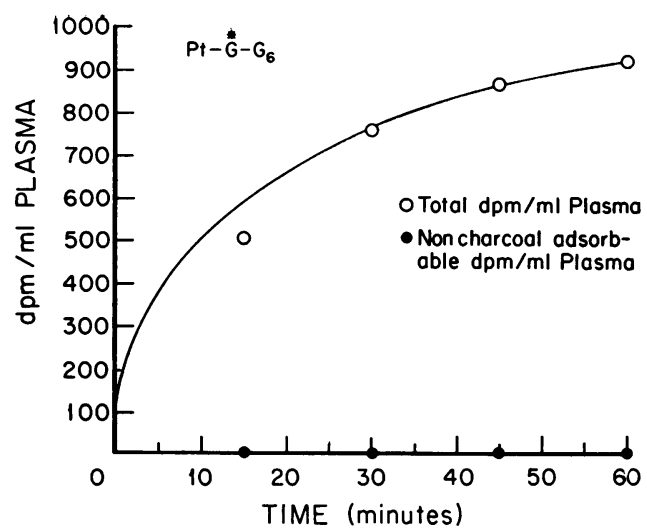

FIGURE 8 Total and noncharcoal adsorbable radioactivity in plasma after the intraluminal injection of $P t-G^{*} G_{6}$ into an isolated jejunal segment.

rate in the segment containing pteroylpentaglutamate was $34 \mathrm{ng} / \mathrm{min}$ per $\mathrm{cm}$ of intestinal length.

C. A solution containing $1 \mu$ mole each of ${ }^{3} \mathrm{H}$-labeled pteroylglutamic acid and pteroylpentaglutamate $-{ }^{14} \mathrm{C}$ was placed into a single isolated segment. The tritium label was located in the $3^{\prime}$ and $5^{\prime}$ positions of the PABA moiety of PGA, while the ${ }^{14} \mathrm{C}$-label of the pentaglutamate was in position 1, the essential glutamate unit of the folate molecule. Differential isotope analysis permitted the measurement of the amount of folic acid absorbed from each form of folate in the mixture. The results are shown in Fig. 7. It may be seen that the monoglutamate leads to more rapid appearance of label than the pentaglutamate. At $20 \mathrm{~min}$ the concentration of label in plasma from the "mono" segment is about twice as great as from the "penta." Due to the location of the ${ }^{14} \mathrm{C}$ label in the pteroylpentaglutamate, it is not possible to state whether there was absorption of folates having more than one glutamate unit in the molecule. However, this experiment clearly provides valid data for comparison and establishes different mechanisms for the absorption of folic acid administered as the monoglutamate as opposed to a polyglutamate form.

\section{Pteroylheptaglutamate}

A. A solution containing $2.75 \mu$ moles of $\mathrm{PtG}^{*}(\mathrm{G})$ 。 was placed in the lumen of a single isolated segment of proximal jejunum. Blood samples of $10 \mathrm{ml}$ each were obtained at 15, 30, 45, and 60-min intervals thereafter, and placed at once into heparinized tubes containing copper chloride. A profile of radioactivity in plasma versus time, with and without charcoal treatment is presented in Fig. 8. Clearly all of the radioactivity is removed from the solution by charcoal indicating that it has remained firmly attached to pteridine, as expected with the label in this position. However, this gives no indication of how many additional glutamate residues, if any, may have remained in the polyglutamyl chain. A partial answer was obtained in the biological folate activities with $S$. faecalis and $L$. case $i$ which indicated comparable curves of uptake, reaching levels of approximately $120 \mathrm{ng} / \mathrm{ml}$ at $30 \mathrm{~min}$, and $275 \mathrm{ng} / \mathrm{ml}$ after $1 \mathrm{hr}$. (See also Fig. 6 and part B. below.) It is of interest to note that at each point, $S$. faecalis activity was slightly greater than $L$. casei, the reverse of what would be expected if folate were being absorbed in a triglutamate form or if methylation had occurred.

All plasma remaining after these preliminary determinations was pooled and added to an equal volume of $10 \%$ trichloroacetic acid. After centrifugation of protein, the supernate was adjusted to $\mathrm{pH} 7.0$ for column chromatography. This solution was pumped onto a standard DEAE-cellulose chloride column and the column thoroughly washed with water. The column was eluted as described, and portions from every other fraction were bioassayed with $S$. faecalis and $L$. casei. A second portion from these fractions was treated with a partially purified conjugase preparation $(9,26)$ and reassayed with $S$. faecalis. The details of procedure and the results are presented in Fig. 9.

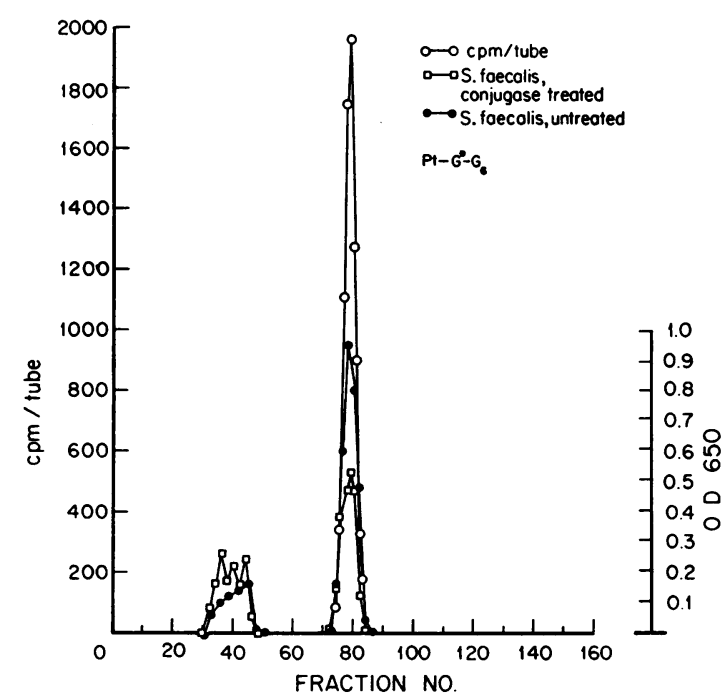

Figure 9 Pt-G* $\mathrm{G}_{6}$ experiment. Radioactivity and microbiological activity before and after conjugase treatment of fractions obtained by DEAE-cellulose chromatography of pooled plasma samples. $S$. faecalis activity before conjugase treatment was determined in $0.1-\mathrm{ml}$ samples. Conjugase treatment was carried out with purified enzyme from liver at $\mathrm{pH} 4.5$ for $2 \mathrm{hr}$ and portions equivalent to $0.05 \mathrm{ml}$ of the original fractions were reassayed. All fractions were assayed. Where no points are shown, the microbiological activity was zero. It may be seen that virtually all of the folate activity in blood emerging from the intestinal segment is in the monoglutamate form. The peak(s) around tube 40 are thought to represent endogenous methyl and formyl derivatives of tetrahydrofolate. 
These results indicate that, during the slow folate absorption which occurs after exposure of the intestinal mucosa to pteroylheptaglutamate, virtually all absorption occurs as the monoglutamate. The low levels of nonradioactive biological activity around tube 40 are believed to represent endogenous folates. (Also see Fig. 4).

Recovery. At the end of the experiment the lumen contents and washings yielded $42 \%$ of the original radioactivity. Unfortunately, the intestinal wall was not saved and it is not possible to determine accurately what portion of the original dose was absorbed into the portal plasma.

B. A solution containing $3.0 \mu$ moles of pteroylheptaglutamate prepared and labeled as in part 6, A (above) was placed in the lumen of a single isolated segment of proximal jejunum. Blood samples were obtained at 5-min intervals for $50 \mathrm{~min}$. A relatively flat absorption curve was obtained on bioassay with both $S$. faecalis and $L$. casei, somewhat higher with the former. The curve of $L$. case $i$ is shown in Fig. 6. The $L$. case $i$ folate activity was $60 \mathrm{ng} / \mathrm{ml}$ at $30 \mathrm{~min}$, and $75 \mathrm{ng} / \mathrm{ml}$ at $50 \mathrm{~min}$. The $S$. faecalis activity at these times was 95 and $135 \mathrm{ng} / \mathrm{ml}$. This curve of uptake was even lower than that in part A (above) although a slightly larger dose of the same compound was employed. Because of small volumes of plasma available, it was not possible to demonstrate significant levels of radioactivity and no further attempt was made to reisolate folate.

\section{DISCUSSION}

The data presented provide information concerning the site of enzymic cleavage of folic acid polyglutamates. In an earlier study (23) it was not possible to determine if cleavage to a monoglutamate form is a prerequisite for intestinal absorption, or if deconjugation of the polyglutamate chain occurred elsewhere after absorption. The present studies demonstrate that the intestinal mucosa of the dog is permeable to both pteroylmonoglutamate and -diglutamate. In this respect the mucosal cell membrane appears to resemble that of $S$. faecalis which is unable to utilize folates having three or more glutamate residues. Thus pteroylmonoglutamate is not an obligatory intermediate in folate absorption from polyglutamate precursors.

Intestinal absorption of pteroyldiglutamate was most readily demonstrable when conditions favored its presence in high initial concentrations. Thus absorption of the diglutamate was regularly observed when pteroyldior triglutamate had been deposited in the lumen, but not with longer chain lengths. In the case of pteroylheptaglutamate it was impossible to detect any form of folate other than the monoglutamate. There does not appear to be a simple explanation for this observation. Evidence has been presented that the folic acid conjugases are exopeptidases $(10,26,27)$ so that one would expect some di- and triglutamates to occur during the course of pteroylpolyglutamate digestion. A possible factor would be the dispersal of folate active material into small pools of varying chain length, with preferential absorption of the monoglutamate. Another factor could be the slow absorption rate, permitting complete cleavage to the monoglutamate derivative during passage through the intestinal mucosa. Further investigations are needed to clarify these points.

Although absorption of $\mathrm{PtGG}^{*}$ was demonstrable in the present study, it is to be emphasized that the monoglutamate appears to be the major and preferred form of folate for absorption. In all situations permitting comparison, the rate and quantity of folate absorption appeared to be greater with the monoglutamate than with any longer chain length. On the other hand it has been observed that urinary excretion tends to be greater after the administration of short chain folates (23). For this reason a high absorption rate is not necessarily associated with good utilization and retention.

When rough comparisons are made as to folate $a b-$ sorption rates (Fig. 6), there appears to be a relative ranking according to chain length, the monoglutamate being absorbed most readily. These findings are in keeping with observations in man (23) which showed greater fecal losses when the longer chains were administered. Jandl and Lear (28) have reported on the relatively greater effectiveness of folate when administered as pteroylglutamate as opposed to a pteroylpolyglutamate derived from yeast.

Whitehead and Cooper (2) have shown that unaltered pteroylglutamic acid is capable of entering the portal circulation in human subjects undergoing umbilical vein catheterization. These observations are confirmed in the present study and extended to include the demonstration of the absorption of pteroylmonoglutamate derived from pteroylpolyglutamates.

Chanarin and Perry ( 3 ) have reported that reduction and methylation occur in the intestine during the absorption of dihydropteroylglutamate in man, and that tetrahydrofolate is methylated. They observed that approximately half of an oral dose of pteroylglutamic acid appeared in the circulation unchanged, and half as the reduced and methylated form. However, their observations were made on blood which had been through the liver so that the site of metabolic alteration was not clearly established. There was no evidence that these alterations occur in the process of absorption in the dog in the experiments and results presented above; the folic acid in mesenteric blood was consistently active for $S$. faecalis and correlated well with both $L$. case $i$ measurements and radioactivity determinations. If $N^{5}$-methyltetrahydrofolate had been formed, it would have supported the growth of 
L. casei only; if unsubstituted tetrahydrofolate had been produced in substantial quantities, one would have expected discrepancies between radioactivity and biological activity since tetrahydrofolate is destroyed by autoclaving (24).

Baker et al. (6) have postulated that pteroylmonoglutamate requires the addition of two gamma glutamyl residues to be absorbed. According to these workers, the higher polyglutamates would require deconjugation to the "triglutamate" stage in order for intestinal absorption to take place. It was suggested that a defect in this system was the cause of nontropical sprue. During the course of the present investigations there was no evidence that glutamic acid residues are added to the molecule at any time during transit from the intestinal lumen to the mesenteric circulation.

Baker et al. (29) reported that synthetic pteroyltriglutamate produced a rise only in $L$. case $i$ activity of systemic plasma after administration to normal subjects. This was interpreted as indicating absorption of the unaltered molecule. However, these results would also be compatible with the formation of $N^{5}$-methyltetrahydrofolate after absorption of the monoglutamate.

Several reports indicate that folic acid is absorbed by an active transport mechanism (5, 25, 30-32). Using a perfusion technique, Hepner (32) presented evidence favoring an active transport mechanism for folate absorption in rat jejunum, but a mechanism of passive diffusion was observed in the ileum. On the basis of experiments with everted intestinal segments, Smith, Matty, and Blair (33) believe that folic acid is absorbed unaltered by an equilibrating, passive process.

Hepner, Booth, Cowan, Hoffbrand, and Mollin (25) studied folic acid absorption in man utilizing a double lumen tube in the intestine to monitor folate disappearance from the intestinal lumen. It was found that the proximal small bowel is the major site of disappearance with relatively little evidence that absorption occurs in the distal ileum. It was observed that absorption continued to take place even against a massive concentration gradient brought about by parenteral administration of folic acid. This would be in keeping with a highly efficient active transport mechanism. It should be pointed out, however, that this study was based on a method which revealed only the disappearance of folate from the lumen. This work has also been the subject of several critical letters to the editor in subsequent issues of the journal in which it was originally published. The data in part 2, B (above) suggest that considerable binding of folate may occur in the intestinal wall and that this phenomenon may not be synonymous with absorption into the portal venous system. Since intestinal mucosal cells may retain other absorbed materials, such as iron, it is conceivable that they may sequester folic acid for a time.

Baker, Thompson, Feingold, and Frank (34) have compared the absorption of pteroylglutamate and pteroyltriglutamate in normal subjects, folate deficient subjects, and in two subjects who had undergone small bowel resection. Their findings suggested that the proximal jejunum is the principal site of folate absorption after administration of the triglutamyl form of folate, although the monoglutamyl form can be absorbed even in the absence of jejunum.

No attempt was made in the present investigations to establish a concentration gradient. However, some indication of the ability of the intestine to absorb folate may be derived from data in the second experiment with pteroyldiglutamate (part 2, B, above). This was an experiment in which all blood emerging from the segment was collected, and this covered only the first $11 \mathrm{~min}$, when the maximum rate had probably not been achieved. Nevertheless, calculations indicate that the segment was absorbing $17 \mathrm{ng}$ of folate/min per $\mathrm{cm}$ of length. Calculations based on folate loss from the lumen would result in even higher figures. In another experiment, absorption rates were observed of $425 \mathrm{ng} / \mathrm{min}$ per $\mathrm{cm}$ of intestine for the monoglutamate and $34 \mathrm{ng} / \mathrm{min}$ per $\mathrm{cm}$ for the pentaglutamate. These rates were observed during the interval 15-20 min after initiating exposure of the lumen to the test material. Hepner et al. (25) reported an absorption rate of $120 \mathrm{ng} / \mathrm{min}$ per $\mathrm{cm}$ of duodenum during perfusion studies in man with a solution of crystalline synthetic folic acid.

It has been shown that $S$. faecalis organisms synthesize polyglutamates from mono- and diglutamyl forms of folic acid taken in through the cell membrane (11). There is further evidence, both direct (27) and indirect (1), that these organisms do not possess enzymes capable of splitting folic acid polyglutamates into units of shorter chain length. This is a situation which would favor the "hoarding" of a scarce growth factor. It may also be a fundamental biological mechanism by which "free" folate is modified producing a "downhill" absorption gradient. It is of interest to note that Bernstein (10) has found the lysosomes of rat liver to contain the highest concentration of gamma glutamyl carboxy-peptidases. Similar results have been found in this laboratory (27). Hoffbrand and Peters (35) in a study of guinea pig intestinal mucosal cells, also found the enzyme in highest concentration in the lysosomal fraction. There was no significant localization of the enzyme in the brush border. These findings would suggest that if pteroylpolyglutamate should enter a cell by phagocytosis, pinocytosis, or other means, it could be subjected to degradation by lysosomal conjugase. Similarly, cells possessing lysosomal conjugase could provide at their 
disruption an environment of conjugase for succeeding generations. It seems likely that this situation prevails in certain species such as the guinea pig in which pancreatic conjugase is reported to be relatively inactive (10). It is of interest to note that a high affinity of the proximal small bowel for pteroylmonoglutamates would favor a high rate of recycling of the folic acid excreted in bile $(19,20)$ as part of an enterohepatic circulation.

We believe that the data, which have been presented, demonstrate that when the intestinal mucosa (of the dog) is exposed to synthetic pteroylpolyglutamate, the principal derivative appearing in the mesenteric circulation is the unaltered pteroylmonoglutamate. Under some conditions pteroyldiglutamate was also absorbed. Although no evidence was found of reduction or substitution under the conditions of these experiments, the data do not exclude the absorbability of folates which have already been reduced and substituted. However, the data indicate that neither reduction, substitution, or cleavage to the monoglutamate stage are essential steps in the absorption of folate from synthetic polyglutamyl precursors. The availability of folate appears to decline progressively as the length of the gamma glutamyl-peptide chain increases. Some cleavage of the polyglutamyl chain apparently takes place in the intestinal lumen, but the data do not rule out the possibility that cleavage also occurred within intestinal mucosal cells. Further studies will be needed to clarify the role of the liver and other tissues in metabolizing folate after absorption has occurred.

\section{ACKNOWLEDGMENTS}

The expert technical assistance of Mrs. Barbara Hudson, Miss Eleanor Braverman, and Mr. Chester Wallace is gratefully acknowledged.

This work was supported by the United States Public Health Service grants AM-08644, AM-11333, and FR00463 ; and by grant $\mathrm{T}-67-\mathrm{K}$ from the American Cancer Society.

\section{REFERENCES}

1. Bird, O. D., S. B. Binkley, E. S. Bloom, A. D. Emmett, and J. J. Pfiffner. 1945. On the enzymic formation of vitamin $B_{c}$ from its conjugate. J. Biol. Chem. 157: 413.

2. Whitehead, V. M., and B. A. Cooper. 1967. Absorption of unaltered folic acid from the gastro-intestinal tract in man. Brit. J. Haematol. 13: 679.

3. Chanarin, I., and Janet Perry. 1969. Evidence for reduction and methylation of folate in the intestine during normal absorption. Lancet. 2: 776.

4. Streiff, R. R., and I. H. Rosenberg. 1967. Absorption of polyglutamic folic acid. J. Clin. Invest. 46: 1121. (Abstr.)

5. Cohen, N. 1965. Differential microbiological assay in study of folic acid absorption in vitro by everted intestinal sacs. Clin. Res. 13: 252. (Abstr.)
6. Baker, H., O. Frank, and H. Sobotka. 1964. Mechanisms of folic acid deficiency in nontropical sprue. J. Amer. Med. Ass. 187 : 119.

7. Hoffbrand, A. V., and T. F. Necheles. 1968. Mechanism of folate deficiency in patients receiving phenytoin. Lancet. 2: 528.

8. Rosenberg, I. H., H. A. Godwin, R. R. Streiff, and W. B. Castle. 1968. Impairment of intestinal deconjugation of dietary folate. A possible explanation of megaloblastic anaemia associated with phenytoin therapy. Lancet. 2: 530 .

9. Baugh, C. M., and C. L. Krumdieck. 1969. Effects of phenytoin on folic acid conjugases in man. Lancet. 2: 519.

10. Bernstein, L. H., S. Gutstein, and S. V. Weiner. 1970. Gamma glutamyl carboxypeptidase (conjugase), the folic acid-releasing enzyme of intestinal mucosa. Amer. J. Clin. Nutr. 23: 919.

11. Wood, R. C., and M. F. Wise. 1965. Conversion of folic acid derivatives to their conjugated forms by cells of Streptococcus fecalis. Tex. Rep. Biol. Med. 23 (Suppl): 512.

12. Wright, B. E. 1956. The role of polyglutamyl pteridine coenzymes in serine metabolism. II. A comparison of various pteridine derivatives. J. Biol. Chem. 219: 873 .

13. Guest, J. R., and K. M. Jones. 1960. Tetrahydropteroyltriglutamate as a cofactor of methionine synthesis. Biochem. J. 75: 12.

14. Large, P. J., and J. R. Quayle. 1963. Microbial growth in $C_{1}$ compounds. V. Enzyme activities in extracts of pseudomonas AMI. Biochem. J. 87: 386.

15. Girdwood, R. H. 1953. Folic acid excretion test in investigation of intestinal malabsorption. Lancet. 2: 53.

16. Cooperman, J. M., A. Pesci-Bourel, and A. L. Luhby. 1970. Urinary excretion of folic acid activity in man. Clin. Chem. 16: 375.

17. Butterworth, C. E., Jr., H. Nadel, E. Perez-Santiago, R. Santini, Jr., and F. H. Gardner. 1957. Folic acid absorption, excretion, and leukocyte concentration in tropical sprue. J. Lab. Clin. Med. 50: 673.

18. Condit, P. T., and D. Grob. 1958. Studies on the folic acid vitamins. I. Observations on the metabolism of folic acid in man and the effect of aminopterin. Cancer. 11: 525.

19. Baker, S. J., S. Kumar, and S. P. Swaminathan. 1965. Excretion of folic acid in bile. Lancet. 1: 685.

20. Creamer, B., and M. Shiner. 1965. Excretion of folic acid in bile. Lancet. 2: 913.

21. Krumdieck, C. L., and C. M. Baugh. 1969. The solidphase synthesis of polyglutamates of folic acid. Biochemistry. 8: 1568 .

22. Merrifield, R. B. 1963. Solid phase peptide synthesis. I. The synthesis of a tetrapeptide. J. Amer. Chem. Soc. 85: 2149.

23. Butterworth, C. E., Jr., C. M. Baugh, and Carlos Krumdieck. 1969. A study of folate absorption and metabolism in man utilizing carbon-14 labeled polyglutamates synthesized by the solid phase method. J. Clin. Invest. 48: 1131.

24. Bakerman, H. A. 1961. A method for measuring the microbiological activity of tetrahydrofolic acid and other labile reduced folic acid derivatives. Anal. Biochem. 2: 558.

25. Hepner, G. W., C. C. Booth, J. Cowan, A. V. Hoffbrand, and D. L. Mollin. 1969. Absorption of crystalline folic acid in man. Lancet. 2: 302. 
26. Baugh, C. M., J. C. Stevens, and C. L. Krumdieck. 1970. Studies on $\boldsymbol{\gamma}$-glutamyl carboxy-peptidase. I. The solid phase synthesis of analogs of polyglutamates of folic acid and their effects on human liver $\boldsymbol{\gamma}$-glutamyl carboxypeptidase. Biochim Biophys. Acta. 212: 116.

27. Baugh, C. M., and C. L. Krumdieck. 1971. Naturally occurring folates. Ann. N. Y. Acad. Sci. In press.

28. Jandl, J. H., and A. A. Lear. 1956. The metabolism of folic acid in cirrhosis. Ann. Intern. Med. 45: 1027.

29. Baker, H., O. Frank, S. Feingold, H. Ziffer, R. A. Gellene, C. M. Leevy, and H. Sobotka. 1965. The fate or orally and parenterally administered folates. Amer. J. Clin. Nutr. 17: 88.

30. Herbert, V., and S. S. Shapiro. 1962. The site of absorption of folic acid in the rat in vitro. Fed. Proc. $21: 260$.
31. Burgen, A. S. V., and N. J. Goldberg. 1962. Absorption of folic acid from the small intestine of the rat. Brit. J. Pharmacol. Chemother. 19: 313.

32. Hepner, G. W. 1969. The absorption of pteroylglutamic (folic) acid in rats. Brit. J. Haematol. 16: 241.

33. Smith, M. E., A. J. Matty, and J. A. Blair. 1970. The transport of folic acid (pteroyl-L-monoglutamic acid) across the small intestine of the rat. Gut. 11: 368.

34. Baker, H., A. D. Thomson, S. Feingold, and O. Frank. 1969. Role of the jejunum in the absorption of folic acid and its polyglutamates. Amer. J. Clin. Nutr. 22: 124.

35. Hoffbrand, A. V., and T. J. Peters. 1969. Subcellular localization of folate conjugase in Guinea-pig intestinal mucosa. J. Physiol. 202: 40 (Abstr.) 